\title{
Food allergies in Indian Children, Time to sensitize clinicians, Now!
}

\author{
DHANASEKHAR KESAVELU ${ }^{1}$, ASHWIN RAVI $^{1}$, and NITHYA FRANKLYN ${ }^{2}$ \\ ${ }^{1}$ Apollo Children's Hospital \\ ${ }^{2}$ Vijaya Hospital
}

June 1,2020

\begin{abstract}
Data is limited or scarce in Indian children on food allergies and their incidence in India. We set to find out the incidence, prevalence, presenting symptoms and the common food allergens in our single center prototype study. To prove the nonexistence of data we searched Scientific databases1,2. Literature review in PubMed/ Google scholar/med base using keywords "Food "+ " allergy" +"statistics "+ "children" + "SAARC countries" didn't reveal any results. Most of the papers related to food allergy were from the Western countries or they were anecdotal Indian data. The growing Indian population, increased usage of processed food, challenges posed by childhood obesity, reduced exposure to external triggers, rising cases of paediatric allergies makes it worthwhile to explore this rather grey area in India. Food allergies will have to be checked comprehensively and various parameters need to be critically analysed before lab- diagnosing food allergy. Increasing awareness in clinician's diagnosis about food allergy and its existence has made us review different studies which have been done in the past few decades. It is an interesting fact to find that there has been no data published in India on this subject and we have attempted to look at an epidemiological cross sectional data of all children who presented with symptoms suggestive of Food allergy, Food protein induced Enterocolitis colitis syndrome or any other related symptoms there in our tertiary centre hospital at Chennai,Tamilndau,India.
\end{abstract}

\section{Hosted file}

allergy and immunology.docx available at https://authorea.com/users/328489/articles/455873food-allergies-in-indian-children-time-to-sensitize-clinicians-now 